\title{
\#WhyITold: A Pilot Test of Twitter Messages Aimed at Promoting Bystander Intervention against Domestic Violence
}

\author{
Norman C. H. Wong ${ }^{1}$, Eryn Bostwick ${ }^{1}$ \\ ${ }^{1}$ The University of Oklahoma, 610 Elm Avenue, Burton Hall, Norman, OK 73019, USA \\ Correspondence: Norman C. H. Wong, The University of Oklahoma, 610 Elm Avenue, Burton Hall, Norman, OK 73019, \\ USA.
}

Received: November 5, 2017

Accepted: December 1, 2017

Online Published: December 1, 2017

doi:10.11114/smc.v5i2.2673

URL: https://doi.org/10.11114/smc.v5i2.2763

\begin{abstract}
This study examined the effectiveness of various messaging via Twitter in persuading bystanders of domestic violence (DV) to intervene on behalf of DV victims. Using Fishbein's (2000) integrative model of behavioral prediction as a guiding framework, an experiment was conducted with 196 undergraduates from a large Southwestern university. Participants were randomly assigned to read either a: (1) tweet describing warning signs associated with DV motivating bystander intervention, (2) gain or loss framed tweet emphasizing why a bystander chose to intervene, or (3) control tweet that simply provided statistics on the prevalence of DV in the U.S. Results indicate injunctive norms were the best predictor of participants' intent to intervene in a DV situation, and that the most effective approach to promoting bystander intervention is to highlight warning signs of DV. Implications for practice are also discussed.
\end{abstract}

Keywords: bystander intervention, social media, integrative model

\section{Introduction}

According to a recent report by the United States Centers for Disease Control (CDC) and Prevention, an estimated 22.3\% of women and $14 \%$ of men experience severe physical violence by an intimate partner (IP), $8.8 \%$ of women and $.8 \%$ of men experience rape by an IP, and $15.8 \%$ of women and $9.5 \%$ of men experience other forms of sexual violence by an IP (Breiding, Smith, Basil, Walters, Chen, \& Merrick, 2014). Unfortunately, an even higher percentage of people (43.9\% of women and $23.4 \%$ of men) have experienced some kind of sexual violence (not necessarily perpetrated by an IP) in their lifetime (Breiding et al., 2014). The numbers do not lie; domestic violence, and abuse more generally, is a problem within the United States. Perhaps even more telling is how much popularity this topic has recently gained in the mass media. In September 2014, after professional football player Ray Rice was released from the Baltimore Ravens team and condemned by National Football League for hitting his then fiancé (now wife) in an elevator, the national spotlight was on the issue of domestic violence (Jarrett, 2014). A Twitter campaign using the hashtags \#WhylStayed and \#WhyILeft even highlighted the struggle victims of domestic abuse go through and sparked a conversation about the national discourse associated with intimate partner violence (IPV) (Lee, 2014).

Considering both the prevalence of domestic abuse, and the recent popularity of the topic, it seems that the time is right for researchers to test a variety of campaigns to help decrease the prevalence of IPV. Using the integrative model of behavioral prediction (IMB; Fishbein, 2000), this study seeks to pilot test a new Twitter hashtag (\#WhyITold) to see the extent the campaign messages impact people's intentions to intervene on behalf of domestic violence victims via altering attitudes, norms, and perceived behavioral control perceptions. Past research on domestic abuse suggests victims often have a hard time finding trusted individuals to whom they feel comfortable disclosing (Petronio, Reeder, Hecht, \& Mont Ros-Mendoza, 1996). Thus, it is important for campaigns to focus on encouraging bystanders to come to the aid of abused victims and let them know they are not alone.

\section{Literature Review}

\subsection{Domestic Violence and Problems of Disclosure}

Domestic violence (DV) can be defined as the emotional and/or physical abuse between family members or intimate partners (Nabi, Southwell, \& Hornik, 2002). According to the CDC 1 in 4 women will experience DV within their lifetime (Jarret, 2014). Although researchers have developed multiple campaigns with the goal of decreasing the 
prevalence of DV (Nabi et al., 2002; Lederman \& Stewart, 2003), it continues to be a major source of pain and suffering for men and women across the country. In fact, research suggests it could significantly increase the risk of mental health problems such as depression, anxiety and thoughts of suicide among victims (Breiding et al., 2014). Furthermore, recent news coverage concerning the prevalence of DV and the experiences of DV survivors has blasted this topic into the spotlight once again.

One of the major concerns surrounding domestic violence is that many victims of abuse do not disclose their situation to others who could potentially help them; therefore, many instances of abuse go undocumented. According to recent research, this is because many people are reluctant to disclose information about abuse and providers are not always willing to ask about it, which limits the opportunities some victims might have to disclose (New York Department of Health and Mental Hygiene, 2008). Furthermore, according to Tolman (1992), abusive acts generally end up resulting in feelings of guilt, fear and powerlessness among victims, which can sometimes lead to silencing. Therefore, victims of abuse deal with a variety of emotions when choosing whether or not to disclose, and have to keep a variety of factors in mind when making their decision.

According to Baxter and Montgomery (1996), when individuals decide whether to disclose information four risks are present: rejection, reduction of personal autonomy and integrity, loss of control or self-efficacy and hurting or embarrassing the listener. With these risks in mind, Shirley, Powers and Sawyer (2007) found that when individuals believe they are being psychologically abused they disclose less often, and when they do disclose they tend to be dishonest about the realities of their situation. Petronio et al. (1996) echoed the sentiments of Baxter and Montgomery and found when sexually abused children consider disclosing, they feel like they need implicit permission from others. Perhaps this is because they are afraid of the reaction others might have, so implicit permission makes them feel more comfortable. Petronio, Flores and Hecht (1997) found children look for characteristics such as credibility, willingness to provide support, willingness to become an advocate, strength, and ability to provide protection to the abused individual when contemplating disclosure.

Although all of these factors are important, for the purposes of this campaign, the most intriguing is the concept of becoming an advocate, providing support and the ability to provide protection. According to Petronio et al. (1997), an advocate is someone who would be willing to relay information about the abuse to those who could help stop it, such as a domestic abuse hotline or the police. This is important because unlike characteristics such as credibility, which is associated with those who have had similar experiences before, campaigns can encourage people to become advocates or at least let victims know others are there for them in their times of need. Similarly, providing support refers to being willing to give victims emotional help and making them feel comfortable discussing their experiences (Petronio et al., 1997). Campaigns could also potentially encourage others to become beacons of hope for abused individuals and help them to understand how important it is to become a trustworthy support system. Lastly, providing protection refers to making sure the abused individual won't feel uncomfortable, guilty or upset when discussing their experiences of abuse (Petronio et al., 1997). Campaigns could also use language that encourages potential disclosure targets to understand the how serious abuse is, and how important it is for victims to feel comfortable in order to disclose. Therefore, it is important that future campaigns focus on helping others to understand how important these characteristics are in the disclosure process, developing these characteristics within potential disclosure targets and encouraging friends and family to let victims know they are available to listen when they are willing to talk. Furthermore, because of the lack of disclosure surrounding abuse, it is also important for researchers and campaign designers to focus on encouraging those who witness abuse to disclose the abuse to someone so the abused individual can get help. With these disclosure considerations in mind, the next section will focus on providing a brief review of previous DV campaign efforts.

\subsection{Review of Past Domestic Violence Campaigns}

There are many factors campaign designers must keep in mind when creating messages about DV. Lederman and Stewart's (2003) formative research concerning message design in DV campaigns provided some much needed insight. According to their focus group data, college students, those who are at a high risk for DV, did not believe the term "domestic violence" applied to the relationships they were in, and therefore were more likely to dismiss messages using the term. They tended to associate DV with marriages and co-habitating romantic relationships instead of simply abuse within an intimate relationship. Participants then suggested campaigns aimed at college-aged individuals should use the term "abusive relationships" instead because it refers to the types of relationships they are likely to be involved in, and encompasses physical, verbal and mental abuse (Lederman \& Stewart, 2003). Their research suggests campaign designers need to focus on using terms that are relevant to their intended audience, as well as those that are as inclusive as possible so individuals don't dismiss the message as irrelevant to them or their loved ones.

Also, when Khosla, Mikami, Frank, Popal, Debeljak and Shaw (2013) disseminated a "Use Your Voice" campaign in Papua New Guinea they found they were able to impact behavioral intentions, but not certain beliefs (e.g., people 
continued to perceive domestic abuse as normative and acceptable following the campaign). People also suggested that DV was a family issue that should be dealt with between family members and/or romantic partners within the home (Khosla et al, 2013). Although their campaign might be considered effective because they were able to improve behavioral intentions to tell someone about instances of DV, the fact that individuals still felt like DV was something that should be taken care of within the home raises concerns.

Keller, Wilkinson and Otjen (2010) also suggested there are some unintended effects DV campaign messages might have without careful consideration. According to their research, if an audience doesn't feel like they have the ability to change abusive behavior, they might not accept the message or could even experience boomerang effects (Keller et al., 2010). Furthermore, acceptance of the message might change based on sex of those who are exposed to the message. Keller et al. (2010) work found that women were significantly more aware of DV services available after exposure to the campaign, had greater perceived response efficacy and were more aware of DV in general than men. Also, women's perceived severity beliefs increased while men's decreased (Keller et al., 2010). Therefore, campaigns need to carefully consider whether their messages might be interpreted differently based on sex.

Lastly, research by Nabi et al. (2002) suggested that campaigns should focus on changing societal norms regarding abuse disclosure. According to Klein, Campbell, Soler and Ghez (1997), when people become aware that someone is being abused, they often ignore it instead of taking action to prevent or stop it. They then suggested if campaigners can change this norm and instead encourage witnesses to take action, rates of domestic violence would be likely to decrease (Klein et al., 1997). Nabi et al.'s (2002) research focused on this approach and found campaigns that increased self-efficacy of witnesses were related to behavioral intentions, but not actual behavior. Furthermore, they found that social norms themselves were significantly related to behavioral intentions, but not behavior itself. The authors suggested future campaigns are still worthwhile, because small changes in social norms could improve rates of abuse overall, but it is obvious there has been a disconnect between behavioral intentions and actual behavior. Therefore, the goal of this campaign is to use a new, potentially more effective, campaign that closes this gap and encourages real behavioral change in the disclosure of DV.

\subsection{Role of Social Network in Motivating Bystander Intervention}

Social network sites have had recent success motivating people to take collective action related to a social concern or issue, such as ALS research (Dewey, 2014), women's rights (Odine, 2013) and the KONY 2012 movement to find Ugandan rebel Joseph Kony (Wasserman, 2012). These campaigns have also gotten widespread media attention, if only for a short amount of time (Dewey, 2014; Wasserman, 2012). The relative success of these campaigns suggests that researchers need to continue to look to social networking sites as a viable option for disseminating campaign messages motivating people to take action against social problems.

A DV campaign that utilizes social network sites, if successful, could continue to keep DV in the national spotlight, which has previously had a positive impact on people's decision to disclose instances of abuse to others. In fact, according to an article in the Huffington Post, within two days after a video that showed NFL running back Ray Rice hitting his fiancée was posted online, the National Domestic Violence Hotline saw an $84 \%$ increase in phone calls (Bassett, 2014). Therefore, it is likely social media may help facilitate greater bystander intervention to aid DV victims in their time of need.

\subsection{Integrative Model of Behavioral Prediction (IM)}

The integrative model (IM; Ajzen \& Albarracín, 2007; Fishbein, 2000, 2008; Fishbein \& Ajzen, 2010) synthesizes variables from the theory of planned behavior, the health belief model, and social cognitive theory into an overarching framework aimed at predicting behaviors. The IM asserts the best predictor of behavior is behavioral intention. The extent to which intention translates into actual behavior depends on whether or not there are environmental constraints and on the person's skills in performing the target behavior. In turn, behavioral intention is predicted by attitudes toward performing the behavior, perceived social norms related to performing the target behavior, and beliefs about one's own abilities to enact the target behavior. Each of these factors are influenced by specific beliefs.

For example, in the current study, attitudes toward intervening in response to a DV situation is expected to be influenced by people's beliefs about the consequences they will face by choosing to intervene, and whether these anticipated outcomes are positive or negative. Perceived social norms related to intervening in a DV situation is mainly influenced by people's beliefs about whether significant others approve or disapprove of the decision to intervene (injunctive norms) and beliefs about how many significant others already intervene in situations involving domestic violence (descriptive norms). Lastly, perceived control in intervening in a DV situation is primarily determined by beliefs about one's ability to successfully perform the target behavior (i.e., intervene on behalf of a DV victim). Each of these determinants of behavioral prediction are said to be impacted by a variety of background (distal) variables (Fishbein, 2000). One distal factor mentioned is exposure to mass-mediated messages (i.e., social media messages). 


\section{Pilot Tweets}

In the present study, the \#WhyITold campaign messages sought to capitalize on the popularity of recent Twitter campaigns (\#HeForShe, \#WhyIStayed, \#FindOurGirls, etc.) to keep issues associated with DV in the national spotlight. This process has been successful in previous campaigns, including a national health campaign in the US (Manderscheid \& Wukitsch, 2014), political campaigns (Wasike, 2012), and a campaign for women's equality in the Middle East (Odine, 2013). In fact, according to Odine's (2013) research, due to a lack of societal support for gender equality, Arab women have utilized social network sites such as Facebook, YouTube and Twitter to get their message out. Because of their effort, the media has started to report on women's inequality issues, more women are enrolling at universities and it seems like women will soon be able to take on career paths normally taken by men (Odine, 2013). This suggests a campaign focused on using Twitter for message dissemination could have potentially far reaching benefits.

Instead of focusing on the behavior of the abused individual, like the \#WhyIStayed campaign did, this pilot campaign seeks to encourage witnesses to the abuse, or those who at least know it is occurring, to become advocates for victims and help support and protect them. Klein et al. (1997) have suggested this approach is a good way to help change societal norms surrounding DV bystander intervention (i.e., it is appropriate to take action). The focus of the study was to test several types of messaging aimed at motivating bystanders to act in response to DV situations. Specifically, one category of tweets highlighted the warning signs of DV (e.g., a partner is very controlling in the relationship). Another category of tweets highlighted reasons people gave for why they chose to intervene framed in either gain or loss terms. A final tweet was included as a comparison message that highlighted DV statistics in the U.S. Due to the fact this is a pilot study, the following set of research questions were posed:

RQ1: What factor(s) from the integrative model significantly predicts people's intentions to intervene on behalf of abused persons?

RQ2: Which message approach has the strongest effect on participants' intent to intervene on behalf of abused persons?

RQ3: Which message approach is perceived to have the most impact on others' intent to intervene on behalf of abused persons?

RQ4: To what extent do normative beliefs vary as a function of the message approach used?

\section{Method}

\subsection{Participants}

One hundred ninety-six undergraduates from a large Southwestern university participated in this study. This is a relevant population because domestic violence is a problem among the college student population (Jacobs \& Poole, 1999; Miller \& Bukva, 2001). In fact, according to the National Intimate Partner and Sexual Violence Survey (2014), the majority of abuse victims were abused before age 25 . Therefore, it is likely that individuals from the college population know someone who has been abused, or have perhaps even witnessed the abuse of a stranger. Participants were recruited using the department's research participant pool (i.e., SONA). In terms of demographic breakdown, the final sample was mainly female $(71.8 \%)$, White $(81.1 \%)$, and had an average age of $20.26(S D=2.59)$. Participants received research or extra credit for their classes by taking part in this study.

\subsection{Procedures}

After consenting to participate in the research and given an option to opt-out of the IRB approved study at any time, the participants completed an online survey (using Qualtrics) which was done to ensure people are as comfortable as possible when dealing with such a sensitive topic. Participants were randomly assigned to 1 of 7 possible message conditions (a control Twitter message, three conditions with Twitter messages focused on warning signs associated with DV, or three conditions with Twitter messages disclosing why someone chose to intervene in a suspected DV situation, framing the rationale in either gain or loss terms (see Appendix A for sample tweets). All of the conditions contained two tweets, one written by a female user and one by a male user. This was done to try to avoid biases related to sex. Those in the control group were exposed to a Twitter message that provided statistics about domestic violence.

For the treatment conditions, each of the 3 tweets encouraged a different action to be taken by the bystander intervening on behalf of the DV victim (i.e., call a national hotline to report the incident, confront the abuser and ask them to cease and desist their abusive behaviors, and talking to the abused offering them social support). All of the treatment messages were developed based on focus groups one of the authors held with 36 participants. During four hour long focus groups, the researchers presented the focus group members with potential Twitter messages and asked the groups to point out those they thought were most effective and those they thought were least effective. Participants also provided feedback about how to make the messages better.

Prior to being exposed to the treatment, individuals completed questions assessing their experience with DV, their 
knowledge about the prevalence of DV and the warning signs associated with DV, their attitudes about whether the three intervention behaviors (i.e. calling a hotline, talking to the abuser, or talking to the abused individual) were effective tactics to deal with abusive situations, perceived norms, perceived behavioral control, and intentions to intervene concerning the three behaviors. Participants were then randomly exposed to one of the groups of tweets. Following message exposure, participants were then asked questions concerning the effectiveness of the messages they saw, and answered the knowledge, attitudes, norms, perceived behavioral control, and intention questions again.

\subsection{Measures}

\subsubsection{Prior Experience with DV}

Participants' prior experience with DV was measured with three items. One asked participants whether or not they have been in an abusive relationship (yes or no), another asked whether they had ever seen a friend be abused by a romantic partner and the last asked how much they believed abusive relationships were a problem among their friend group (not a problem, minor problem, moderate problem or major problem).

\subsubsection{Knowledge about Warning Signs}

Knowledge about warning signs associated with DV were measured by presenting participants with scenarios and asking them to rate whether the situation was considered a DV situation. These scenarios were created based on the warning signs listed on the National Domestic Violence Hotline webpage. Responses were provided on a 5 point Likert-type scale $(1=$ definitely not domestic violence to $5=$ definitely domestic violence). Example scenarios include, "Brendan's girlfriend constantly tells him that he can't do anything right" and "Brad suspected his girlfriend was lying to him so he slapped her across the face." Some scenarios were more direct in illustrating DV whereas others had more subtlety. The items were combined into an index yielding a reliability score of $\alpha=.66$. This measure served as a covariate in analyses.

\subsubsection{Perceived Prevalence of DV}

Participants were also asked how common of a problem they thought relational abuse/violence was in the United States, as well as at the university in which they were enrolled $(1-$ not a problem to $10=$ the biggest problem). Overall, respondents perceived relational abuse/violence in the United States $(M=6.84, S D=1.31)$ and at the university where the study was conducted $(M=5.49, S D=1.89)$ to be a moderate concern.

\subsubsection{Attitudes toward Intervening}

Attitudes were measured using semantic differential scales. Specifically, five items asked whether participants felt it appropriate and important for someone to engage in each of the three behavior outcomes (e.g., I believe people calling a domestic violence hotline if someone they know is being abused is inappropriatelappropriate, wrong/right, unimportant/important). Reliabilities ranged from $\alpha=.89$ to $\alpha=.92$ for the pretest, and from $\alpha=.90$ to $\alpha=.92$ for the posttest.

\subsubsection{Perceived Behavioral Control (PBC)}

PBC was measured using a 5 point Likert-type scale $(1=$ strongly disagree to $5=$ strongly agree $)$ asking a $)$ whether participants thought an intervention behavior was within their control, b) if they had the ability to engage in the intervention behavior, c) if they had confidence in their ability to carry out the intervention behavior, and d) whether engaging in the intervention behavior was within their power. These questions were asked for each of the three behavioral outcomes. Reliabilities ranged from $\alpha=.81$ to $\alpha=.86$ for the pretest, and from $\alpha=.76$ to $\alpha=.85$ for the posttest.

\subsubsection{Intent to Intervene}

Participants' intentions to intervene in a DV situation were measured by asking participants whether they would take action if they witnessed domestic violence on a 5 -point Likert-type scale $(1=$ strongly disagree to $5=$ strongly agree $)$. Four items were used (e.g., I think I would step in and do or say something if I saw a friend of mine being abused) yielding acceptable reliabilities for the pretest $(\alpha=.78)$ and for the posttest $(\alpha=.81)$.

\subsubsection{Perceived Norms}

Two sets of items were used to assess perceived social norms related to intervening in DV situations. First, participants were asked the extent to which they believe they should help out others if there is suspected domestic abuse. Seven items assessed injunctive norms related to intervening in a DV situation (e.g., I believe people have an obligation to help others if they believe they are in an abusive relationship) on a 5-point Liker-type scale ( $1=$ strongly disagree, $5=$ strongly agree). Reliabilities were acceptable for the pretest $(\alpha=.70)$ and posttest $(\alpha=.75)$.

Second, participants were asked how often they thought others intervened in a DV situation using three items on a 
5-point Likert-type scale $(1=$ never to $5=$ very often $)$. Descriptive norms related to intervening in a DV situation via three different actions (calling a domestic hotline, confronting the abuser, and talking to the abused person to offer social support) were assessed separately. Specifically, participants were asked to respond to questions such as, "How often do you believe people call a domestic violence hotline if they think someone they know is being abused?" Combining the items yielded poor reliability and so the descriptive norm items were analyzed as single item measures.

\subsubsection{Perceived Impact on Others}

To determine whether the messages were effective, participants were asked what they feel the impact would be on others if they read the tweets using six items on a 5 -point Likert-type scale $(1=$ strongly disagree to $5=$ strongly agree $)$. Participants were asked to what extent they agreed with statements such as, "Others who read these tweets are likely to help a friend they believe is in an abusive relationship" and "Others who read the tweets would probably go on with their lives as normal if they think their friend might be in an abusive relationship." Overall, the items yielded acceptable reliability $(\alpha=.76)$.

\section{Results}

\subsection{Research Question One}

To answer RQ1, a hierarchical multiple regression was performed with intentions to intervene regressed onto attitudes, injunctive norms, descriptive norms, and perceived behavioral control related to calling a hotline, talking to the abuser, or talking to the abused person. Controlling for pretest measures, prior experience with DV, and knowledge about DV, collapsing across all message conditions, the overall model was significant, $F(12,182)=43.11, p<.001$, adjusted $R^{2}=.72$. Intent to intervene was significantly predicted by injunctive norms $(\beta=.28, t=4.53, p<.001)$.

\subsection{Research Question Two}

An analysis of covariance (ANCOVA) was used to test for differences in impact of message approaches (warning signs, gain/loss framing of bystander motivation, control) on respondents' intentions to intervene. Participants' intent to intervene on behalf of abused persons significantly varied by message approach, $F(2,185)=6.02, p<.01, \eta^{2}=.025$. Specifically, tweets that highlighted the warning signs of DV $(M=4.29, S E=.07)$ significantly yielded higher intent to intervene among participants than the control message $(M=3.71, S E=.16)$. Tweets that focused on sharing reasons why a person chose to intervene using gain or loss message frames $(\mathrm{M}=4.06, S E=.07)$ was also somewhat effective at motivating intentions to intervene (see Figure 1). Pretest intent, prior experience with DV, and knowledge of DV served as covariates.

\subsection{Research Question Three}

An ANCOVA was used to test for differences in perceived impact on others' intentions to intervene as a function of the message approach. No significant differences across the three message conditions were found, $F(2,186)=2.83, p=.06$. Overall, respondents felt the tweets would not have much impact on others' intent to intervene as a bystander in situations involving DV (see Figure 1). Prior experience with DV, and knowledge of DV served as covariates.

\section{Intent to Intervene \& Perceived Impact by Message Strategy}

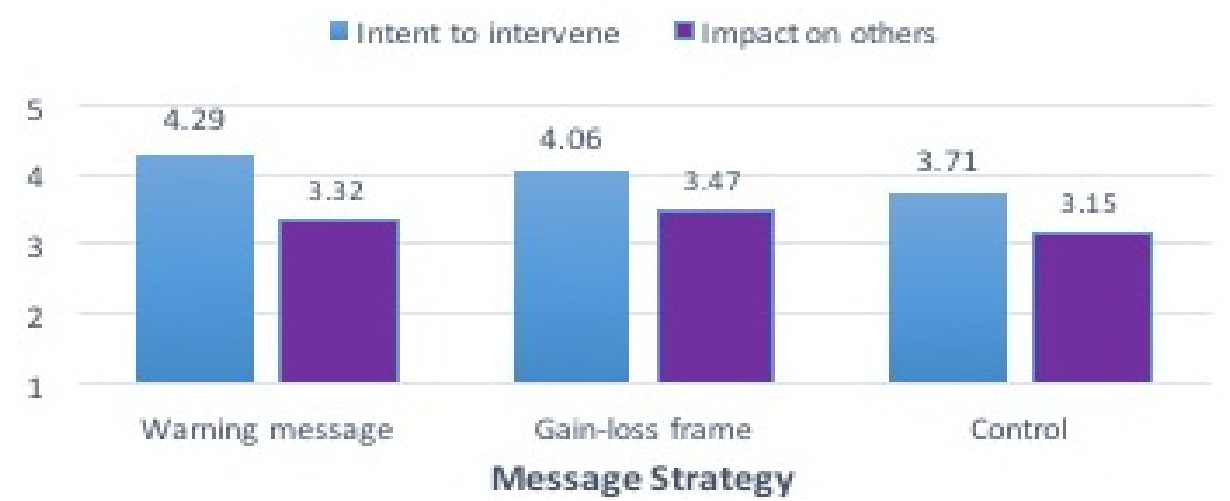

Figure 1. Intent to Intervene \& Perceived Impact by Message Strategy

\subsection{Research Question Four}

An ANCOVA was performed on the data set to look at how normative beliefs varied across the three message approaches. Separate analyses were done for injunctive and descriptive norms. Regarding injunctive norms, the overall 
model was significant, $F(2,185)=5.01, p<.01, \eta^{2}=.021$. Specifically, tweets that highlighted the warning signs of DV $(M=4.01, S E=.05)$ yielded stronger injunctive norms regarding intervening in a DV situation compared to tweets of gain or loss framed messages talking about reasons why someone chose to intervene $(M=3.92, S E=.05)$ or a control tweet $(M=3.71, S E=.08$; see Figure 2).

Concerning descriptive norms, interestingly, there were no significant differences across the three message approaches, $F(2,185)=0.30, p=.74$. Overall, respondents reported relatively low descriptive norms concerning bystander intervention in situations involving DV (i.e., means were below 3 on a 5-point scale). In other words, participants felt that not many people would intervene as a bystander of DV.

\section{Normative Beliefs by Message Strategy}

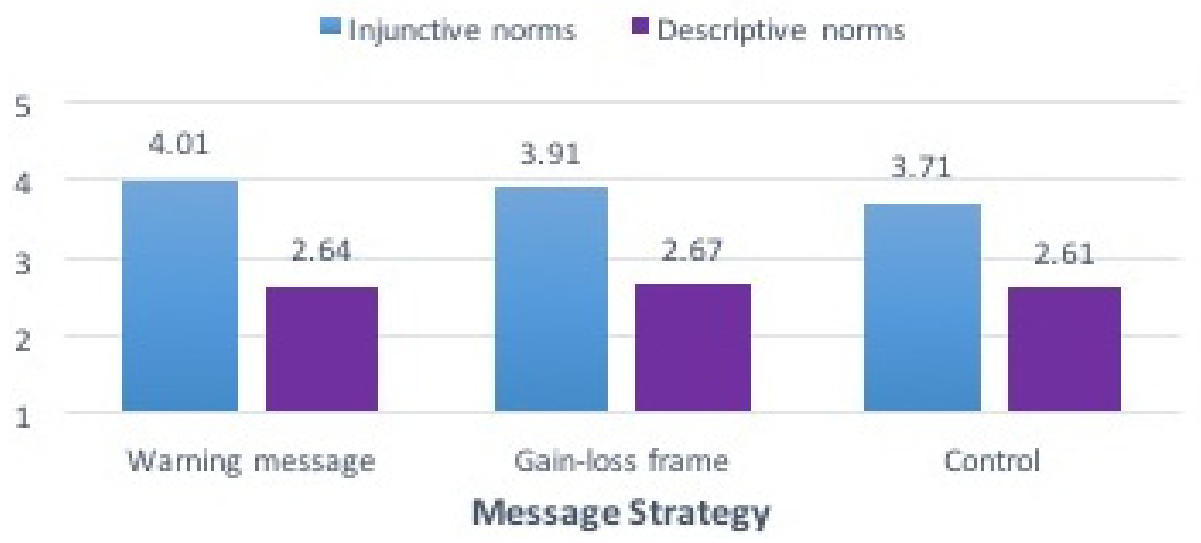

Figure 2.Normative Beliefs by Message Strategy

\section{Discussion}

The purpose of this study was to pilot test two different approaches to motivating bystander intervention in the context of domestic violence. Specifically, messages distributed via social media (Twitter) were shown to participants either highlighting the warning signs people should look for when suspecting DV is occurring to a friend or stranger or messages discussing the reasons why a bystander chose to intervene using gain or loss message framing. Overall, several conclusions can be drawn from the data. First, injunctive norms were found to be the strongest predictor of intent to intervene on behalf of an abused person. This implies DV campaigns should target injunctive norms in order to motivate collective actions by bystanders of DV to step in and help those they suspect as being victims of DV. Specifically, campaign messages should emphasize the moral obligations people have to do something when they witness or suspect DV is happening to someone they know (i.e., inaction on their part may imply DV is an acceptable behavior in society).

Interestingly, neither attitudes toward intervening nor perceived behavioral control related to bystander intervention were significant predictors, when controlling for the other factors in the integrative model. Overall, participants reported positive attitudes toward intervening in a DV situation $(M=4.26, S D=.63)$ and perceived high levels of control in their abilities to intervene on behalf of someone being abused by another person $(M=4.34, S D=.60)$. Presently, many campaigns aimed at DV prevention seem to focus mainly on increasing awareness of the prevalence of the problem (e.g., citing statistics of how many women and men are victims of domestic and relationship abuse/violence). While it is important for people to be aware about the extent to which DV is a public health concern, campaigns may be more effective if they focused their efforts on communicating the message that others, particularly those who are victims of DV, would want us to intervene on their behalf even if they do not directly express their concerns to us.

Second, our results found messages highlighting warning signs of DV produced the strongest effects on participant's intent to intervene in a DV situation, primarily via influencing perceptions of injunctive norms. It appears an effective strategy for communicating the message that people should do something when faced with a DV situation may not necessarily involve directly expressing the sentiment, but rather can be indirectly communicated via simply talking informing people of the warning signs to look for related to DV. This is encouraging given that some current DV campaigns already take this approach to help prevent DV or relational abuse (e.g., Red Flags campaign, Borsky, McDonnell, Turner, \& Rimal, 2016). Future DV campaigns aimed at increasing bystander intervention should continue to highlight warning signs as opposed to simply providing statistics about DV to motivate collective action in addressing this problem. 
Lastly, social media may work as an effective channel for distributing campaign messages aimed at promoting greater bystander intervention in DV situations. This study provides empirical support to show how social media can be incorporated into larger mass media campaigns aimed at DV prevention. Reliance on social media such as Facebook and Twitter can quickly help disseminate campaign messages to a wide audience, and makes it easy for the message to spread across social networks (via sharing on Facebook or retweeting on Twitter). Future studies may also want to explore different ways of communicating warning signs other than relying on text (e.g., using pictures to illustrate the warning signs or "red flags" people should look for that someone is being abused and posting them on Instagram or Snapchat).

Like most studies, there are some limitations worth noting in our current investigation. First, participants were not exposed to the tweets as part of their daily social media interactions. In other words, while the messages were created to look like actual tweets from individuals, they were presented within an experimental context rather than delivered to participants' actual Twitter accounts. Future studies may explore the possibility of sending out the tweets to participants' actual Twitter accounts via a closed group to enhance the realism of the situation. Second, the present study only examined people's intent to intervene in a DV situation. Follow-up surveys would be needed to determine to what extent people actually intervened in DV situations involving their friends or others they suspect are being abused in their relationships. Future studies may consider using a longitudinal design to track changes in people's intervention behavior in DV situations over several weeks or months to determine the actual impact of campaign messages aimed at promoting bystander intervention.

In conclusion, this was an initial pilot study to test alternative message approaches for motivating actions to prevent DV or relational abuse other than simply providing statistics to highlight the prevalence of the problem. Domestic violence continues to be a public health problem that needs to be addressed by public health communicators. Future studies may also explore other similar public health concerns such as sexual violence (e.g., sexual assault, rape, sexual harassment) to determine whether similar message approaches (i.e., highlighting warning signs) can be used to promote greater bystander intervention in those situations as well.

\section{References}

Ajzen, I., \& Albarracín, D. (2007). Predicting and changing behavior: A reasoned action approach. In I. Ajzen, D. Albarracín, \& R. Hornik (Eds.), Prediction and change of health behavior (pp. 1-22). Mahwah, NJ: Lawrence Erlbaum.

Baxter, L. A., \& Montgomery, B. M. (1996). Relating: Dialogues and dialectics. New York: The Guilford Press

Borsky, A. E., McDonnell, K., Turner, M. M., \& Rimal, R. (2016). Raising a red flag on dating violence: Evaluation of a low-resource, college-based bystander behavior intervention program. Journal of Interpersonal Violence, https://doi.org/10.1177/0886260516635322

Breiding, M. J., Smith, S. G., Basile, K. C., Walters, M. L., Chen, J., \& Merrick, M. T. (2014, Sept 5). Prevalence and characteristics of sexual violence, stalking, and intimate partner violence victimization: National intimate partner and sexual violence survey, United States, 2011. Retrieved from

http://www.cdc.gov/mmwr/preview/mmwrhtml/ss6308a1.htm?s_cid=ss6308a1_e

Fishbein, M. (2000). The role of theory in HIV prevention. AIDS Care, 12, 273-278. https://doi.org/10.1080/09540120050042918

Fishbein, M. (2008). A reasoned action approach to health promotion. Medical Decision Making, 28, 834-844. https://doi.org/10.1177/0272989X08326092

Fishbein, M., \& Ajzen, I. (2010). Predicting and changing behavior. New York, NY: Taylor \& Francis.

Jacobs, S. A., \& Poole, L. M. (1999). Violence in America: A public health crisis-domestic violence (The Violence Prevention Task Force of the Eastern Association for the Surgery of Trauma). Journal of Trauma, 46, 1105-1113. https://doi.org/10.1111/josh.12046

Keller, S. N., Wilkinson, T., \& Otjen, A. J. (2010). Unintended effects of a domestic violence campaign. Journal of Advertising, 39, 53-67. https://doi.org/10.2753/JOA0091-3367390404

Khosala, V., Mikami, A., Frank, L. B., Popal, I., Debeljak, K., \& Shaw, A. (2013). Combating violence against women through C4D: The "use your voice" campaign and its implications on audience-citizens in Papua New Guinea. International Journal of Communication, 7, 2087-2104.

Klein E., Campbell J., Soler E., \& Ghez M. (1997) Ending domestic violence: Changing public perceptions/halting the epidemic. London: Sage. 
Lederman, L. C., \& Stewart, L. P. (2003). Using focus groups to formulate effective language for health communication messages: A media campaign to raise awareness of domestic violence on a college campus. Qualitative Research Reposts in Communication, 4, 16-22.

Manderscheid, R., \& Wukitsch, K. (2014). Health people 2020: Developing the potential of mobile and digital communication tools to touch the life of every American. Journal of Communication in Healthcare, 7, 8-16. https://doi.org/10.1179/1753807614Y.0000000043

Miller, J., \& Bukva, K. (2001). Intimate violence perceptions: Young adults' judgments of abuse escalating from verbal arguments. Journal of Interpersonal Violence, 16, 133-150. https://doi.org/10.1177/088626001016002003

Nabi, R. L., Southwell, B., \& Hornik, R. (2002). Predicting intentions versus predicting behaviors: Domestic violence prevention from a theory of reasoned action perspective. Health Communication, 14, 429-449. https://doi.org/10.1207/S15327027HC1404_2

National Intimate Partner and Sexual Violence Survey (2014). [Infographic of Statistical Data Concerning Intimate Partner Violence and Stalking Prevalence]. Prevalence and characteristics of sexual violence, stalking, and intimate partner violence victimization: National intimate partner and sexual violence survey, United States, 2011. Retrieved from http://www.cdc.gov/violenceprevention/nisvs/infographic.html

Odine, M. (2013). Arab women use media to address inequality. Journal of International Communication, 19, 167-181. https://doi.org/10.1080/13216597.2013.833537

Petronio, S., Flores, L. A., \& Hecht, M. L. (1997). Locating the voice of logic: Disclosure discourse of sexual abuse. Western Journal of Communication, 61, 101-113. https://doi.org/10.1080/10570319709374565

Petronio, S., Reeder, H. M., Hecht, M. L., \& Mont Ros-Mendoza, T. M. (1996). Disclosure of sexual abuse by children and adolescents. Journal of Applied Communication Research, 24, 181-199. https://doi.org/10.1080/00909889609365450

Shirley, J. A., Powers, W. G., \& Sawyer, C. R. (2007). Psychologically abusive relationships and self-disclosure orientations. Human Communication, 10, 289-302. Retrieved from http://www.uab.edu/Communicationstudies/humancommunication/PARSDO,2007,289-302.pdf

Tolman, R. M. (1992). Psychological abuse of women. In R.T. Ammerman \& M. Hersen (Eds.), Assessment of family violence: A clinical and a legal source book (pp. 291-310). New York: Wiley.

Wasike, B. S. (2012). The republican primaries in 140 characters: How the 2012 candidates used Twitter to mobilize their supporters, interact with them and frame the campaign. Southwestern Mass Communication Journal, 27, $1-33$.

New York Department of Health and Mental Hygiene. (2008, Oct). Intimate partner violence: Encouraging disclosure and referral in the primary care setting. Retrieved from http://www.nyc.gov/html/doh/downloads/pdf/chi/chi27-suppl2.pdf

Wasserman, T. (2012, March 12). 'KONY 2012' tops 100 million views, becomes the most viral video in history. Mashable. Retrieved from http://mashable.com/2012/03/12/kony-most-viral/\#pOEA0ceG1Eqs

Dewey, C. (2014, Aug 12). Stop hating on the ice bucket challenge: It's raised millions of dollars for charity. The Washington Post. Retrieved from http://www.washingtonpost.com/news/the-intersect/wp/2014/08/12/stop-hating-on-the-ice-bucket-challenge-its-rai sed-millions-of-dollars-for-charity/

Bassett, L. (2014, Sept 10). Ray Rice video causes huge spike in calls to domestic violence hotline. Huffington Post. Retrieved from http://www.huffingtonpost.com/2014/09/10/ray-rice-domestic-violence- hotline_n_5798462.html

Jarrett, T. (2014, Sept 10). Why She stayed: Ray Rice video sheds light on domestic violence. NBC News. Retrieved from

http://www.nbcnews.com/storyline/nfl-controversy/why-she-stayed-ray-rice-video-sheds-light-domestic-violencen200266

Lee, J. (2014, Sept 10). \#WhyIStayed: Powerful stories of domestic violence. USA Today. Retrieved from http://www.usatoday.com/story/news/nation-now/2014/09/10/why-i-stayed-hashtag-twitter-ray-rice/15385027/ 


\section{Appendix A}

\section{Warning Signs/Hotline:}

My friend wasn't in class again. Something seemed off. I was worried it was because of the new relationship. The hotline helped. \#WhyITold.

She said he pressured her to have sex and she felt ashamed. I wanted to help, but needed advice so I called the hotline \#WhyITold.

\section{Warning Signs/Talking to Abuser:}

We were sick of hearing all of the putdowns, so we felt like we had to stand up to it \#WhyITold.

She never wanted him to hang around with us anymore and was too controlling. We missed our friend so we had to talk to her \#WhyITold.

\section{Warning Signs/Talking to Abused:}

Every time we went out she commented about how stupid he was. That isn't okay. I had to reach out to him. \#WhyITold.

Because I wanted her to know I noticed the jealousy too. It wasn't in her head and I wanted her to be able to talk to someone. \#WhyITold.

\section{Gain-Loss/Hotline:}

Because calling the hotline was the only way I knew how to help \#WhyITold.

Because when I saw the bruises, I was afraid if I didn't call the hotline it would get worse \#WhyITold.

\section{Gain-Loss/Talking to Abuser:}

Because I knew if I confronted him she might feel safe \#WhyITold.

Someone needed to talk to her, her criticism had just gone too far \#WhyITold.

\section{Gain-Loss/Talking to Abused:}

Because she needed an advocate. Talking to her gave her strength \#WhyITold.

Because if I didn't talk to him about it, he might not have gotten help \#WhyITold.

\section{Control:}

1 in 3 women and 1 in 4 men have been victims of some form of physical violence by an intimate partner within their lifetime.

Women between the ages of 18-24 are most commonly abused by an intimate partner.

\section{Copyrights}

Copyright for this article is retained by the author(s), with first publication rights granted to the journal.

This is an open-access article distributed under the terms and conditions of the Creative Commons Attribution license which permits unrestricted use, distribution, and reproduction in any medium, provided the original work is properly cited. 